\title{
Effects of Prolotherapy with Organic Silicon in Temporomandibular Joint in Rabbits
}

\author{
Mehmet Emre Yurttutan' (D), Uğur Gülșen² (1) \\ 'Department of Oral and Maxillofacial Surgery, Ankara University Faculty of Dentistry, Ankara, Turkey \\ 2Department of Oral and Maxillofacial Surgery, Zonguldak Bülent Ecevit University Faculty of Dentistry, Zonguldak, Turkey
}

ORCID iDs of the authors: M. E. Y. 0000-000I-9796-5738; U. G. 0000-0003-I282-2936.

Cite this article as: Yurttutan ME, Gülșen U. Effects of Prolotherapy with Organic Silicon in Temporomandibular Joint in Rabbits. Cyprus J Med Sci 2020; 5(2): II7-20.

\section{BACKGROUND/AIMS}

Temporomandibular joint (TMJ) hypermobility is characterized by condyle hypertranslation, which moves anteriorly to the articular eminence as the mouth opens. This study investigated the efficacy of organic silicon prolotherapy for treating TMJ hypermobility.

\section{MATERIAL and METHODS}

The study sample consisted of six young New Zealand White rabbits. One of the rabbit's TMJ's was injected with organic silicon while the other joint was injected with isotonic saline. Isotonic saline $(1.5 \mathrm{~mL})$ was bilaterally administered into the upper joint space $(I \mathrm{~mL})$ and pericapsular tissue $(0.5 \mathrm{~mL})$. The rabbits were sacrificed using high-dose anesthetics one month after the follow-up. The sample sections were stained with Mallory-Azan dye in order to identify collagen fibers. The samples were analyzed in terms of fibrosis and tissue reactions. Statistical analysis was performed using the Mann-Whitney U test.

\section{RESULTS}

There was a significant difference in the severity of fibrosis amongst the study groups ( $p=0.00512)$. It was noted that more collagen fibers and adipose tissue were produced from organic silicon than saline in the retrodiscal ligament.

\section{CONCLUSION}

The study concluded that organic silicon could be used as an alternative to dextrose injection for prolotherapy. Future studies and clinical trials are necessary to gain further insight.

Keywords: Organic silicon, prolotherapy, TMJ hypermobility

\section{INTRODUCTION}

Temporomandibular joint (TMJ) hypermobility is defined as the hypertranslation of the condyle. The condylar head moves anteriorly to the articular eminence as the mouth opens (I). The terms "subluxation," "luxation," and "dislocation" have been used to describe this phenomenon (2). TMJ dislocation can be an acute or a recurrent problem. It occurs when the condyle moves outside the glenoid fossa, locks anteriorly to the articular eminence, and cannot be self-reduced $(3,4)$.

The cause of TMJ hypermobility is linked to the morphology of the mandibular condyle-glenoid fossa-articular eminence and generalized joint laxity (5). Some actions that contribute to TMJ hypermobility include yawning, trauma, wide biting, intubation with general anesthesia, connective tissue disorders, tooth extraction, occlusal discrepancies, and lost vertical dimension which increases capsule weakness and ligament laxity (6).

TMJ hypermobility can be treated using surgical or conservative techniques. Surgical procedures may include condylectomy, lateral pterygoid myotomy, capsular plication, and augmentation or reduction of the articular eminence (I, 7-9). Other conservative treatment approaches include physiotherapy, prolotherapy occlusal splints, intermaxillary fixation, intramuscular injection of botulinum toxin or sclerosing solutions, and intra-articular autologous blood injections $(10,11)$. 
Prolotherapy, or "proliferation treatment," is also known as "regenerative injection therapy" and "growth factor stimulation injection therapy." Since 1937, it has been used to strengthen and repair chronic ligaments, capsules, joints, and tendinous injuries through the stimulation of collagen proliferation at the fibro-osseous junctions, which promotes the repair of soft tissues and relieves pain (12). Prolotherapy primarily stimulates a small inflammatory response that promotes healing and/or viable scar tissue formation which leads to stronger fibrous tissue at the TMJ capsule and ligaments. Consequently, it inhibits the condyle from locking in an abnormal position in front of the articular eminence (I3).

Prolotherapy involves the use of various agents such as pumice flour, phenol, sodium morrhuate (14), combinations of dextroseglycerin-phenol, psyllium seed oil (I5), and various concentrations of dextrose (I6).

Organic silicon is one of the most widely used drugs in mesotherapy. It is a structural component of connective tissue and is an important part of both elastin and collagen. It controls the increase in fibroblast numbers and promotes the regeneration of elastin and collagen fibers. Silicon also stimulates and regulates the mitosis of fibroblasts. The mechanism of action that is used in organic silicon is similar to that of prolotherapy (17).

The most common substance used in prolotherapy is dextrose. However, Kılıc et al. showed that dextrose has had no superiority and does not contribute to the treatment of hypermobility when compared with isotonic saline (18). Based on this finding, it is believed that prolotherapy can be performed with a novel material that has not been previously explored. Therefore, proliferation was tested in this study with a component containing organic silicon.

\section{MATERIAL and METHODS}

Gazi University, Animal Experiments Local Ethics Committee (G.Ü.ET-I6.004/04.02.2016) The bilateral TMJs of six male New Zealand White rabbits (approximately I-year-old, weighing 2.5-3.0 kg) were assessed. The maximum number of animals that the ethics committee allowed was used in this study to achieve the minimum number of animals needed to generate statistically significant data. The rabbits' health was observed for seven days before the study. The rabbits were housed in standard-sized individual cages with consistent humidity and temperature (approximately $60 \%$ and $22{ }^{\circ} \mathrm{C}$, respectively) under a I2-h light/dark cycle. They were fed a standard laboratory diet with water ad libitum.

\section{Main Points:}

- Prolotherapy is one of the conservative treatments currently being used in hypermobility of temporomandibular joint.

- In general, dextrose is used in prolotherapy. However, there is currently no standard set for the concentration of dextrose. This uncertainty propels researchers to research different materials that can be used in prolotherapy.

- Organic silicon may be one such material that can achieve the necessary histological results for prolotherapy.
Each rabbit was given both injection groups. One side of the TMJs received an organic silicon (Conjonctyl, sodium monomethyl trisilanol orthohydroxybenzoate, $5 \mathrm{~mL}$, Sedifa Laboratory, France) injection (six TMJs). The contralateral sides of TMJs were injected with an isotonic saline (six TMJs). The rabbits were injected intramuscularly with ketamine hydrochloride $(35 \mathrm{mg} / \mathrm{kg}$ ) and xylazine $(5 \mathrm{mg} / \mathrm{kg}$ ) as anesthesia. First, the preauricular region was shaved and the injection site (as specified by Artuziet et. al (19) was disinfected using povidone-iodine. Then, a 28-gauge needle was used to inject organic silicon into the upper space of the TMJ $(\mathrm{mL})$ and the pericapsular tissues $(0.5 \mathrm{~mL})$. Similarly, the control group was injected with isotonic saline: I $\mathrm{mL}$ into the upper space of the TMJ and $0.5 \mathrm{~mL}$ into the pericapsular tissues.

Orthodontic brackets were used for one day on the mandibles to prevent the elongation of newly forming fibrous tissues. No postoperative medication was used. The rabbits were sacrificed one month after the experimental period. Ketamine hydrochloride $(45 \mathrm{mg} / \mathrm{kg}$ ) and xylazine $(5 \mathrm{mg} / \mathrm{kg}$ ) were intramuscularly injected to maintain deep anesthesia. Afterwards, $20 \mathrm{mg}$ xylazine was injected into the pinna vein to sacrifice the rabbits while they were anesthetized. The TMJ regions were then dissected and fixed in a 10\% buffered formalin solution for $72 \mathrm{~h}$.

The samples were decalcified with an $8 \%$ hydrochloric acid and $8 \%$ formic acid solution. The paraffin blocks were sliced to a thickness of $6 \mu \mathrm{m}$ using a Leica RM 2I25RT. The TMJ sections were stained with Mallory-Azan dye to identify collagen fibers for evaluation of fibrosis and tissue reactions in the samples. Routine light microscopy techniques were used.

The guidelines established by Sairyo et al. (20) were used to assess fibrosis severity in retrodiscal ligaments and the lateral capsular ligaments (Grade 0: normal tissue showing no fibrotic regions, Grade I: $<25 \%$ fibrosis of the entire area, Grade 2: 25\%-50\% fibrosis, Grade 3: 50\%-75\% fibrosis, and Grade 4: > 75\% fibrosis).

The statistical calculations were performed using Statistical Package for the Social Sciencesl8 software (SPSS Inc., Chicago, IL, USA). The Mann-Whitney U-test was used to estimate the differences in fibrosis severity among the study groups. Statistical significance was accepted as $p<0.05$.

\section{RESULTS}

The rabbits in the study underwent the procedure with no complications. Two independent observers, who were unaware of the treatment groups, performed the histopathological examination.

When the articular fibrous disk between the temporal and mandibular bones and the subsequent retrodiscal ligament were examined, it was noted that there was an increase in inflammation of the organic silicon group, especially in the region where the ligament was attached to the posterior part of the temporal bone. It was also observed that there was proliferation of chondrocytes, increased amount of chondral tissue, and cell activation in the area where the temporal bone adhered to the ligament and also on the surface facing the disk. Inflammatory and adipocyte cells, as well as collagen fibers, were also commonly observed in the fibrous articular disk (Figure I). Thin bundles of collagen fibers, adipocytes, and fibrin accumulation were observed in collateral ligaments in the isotonic saline group. Inflammation was not detected (Figure I). 


\begin{tabular}{|lccccccc|}
\hline TABLE I. Severity of fibrosis in areas of the temporomandibular joint injected with organic silicon and isotonic saline \\
\hline Treatment Groups & $\mathbf{n}$ & Grade 0 & Grade I & Grade 2 & Grade 3 & Grade 4 & Mann Whitney U test p \\
\hline Saline-injected & 6 & 6 & 0 & 0 & 0 & 0 & 0.00512 \\
Organic silicon-injected & 6 & 0 & 2 & 3 & I & 0 & 0 \\
\hline
\end{tabular}

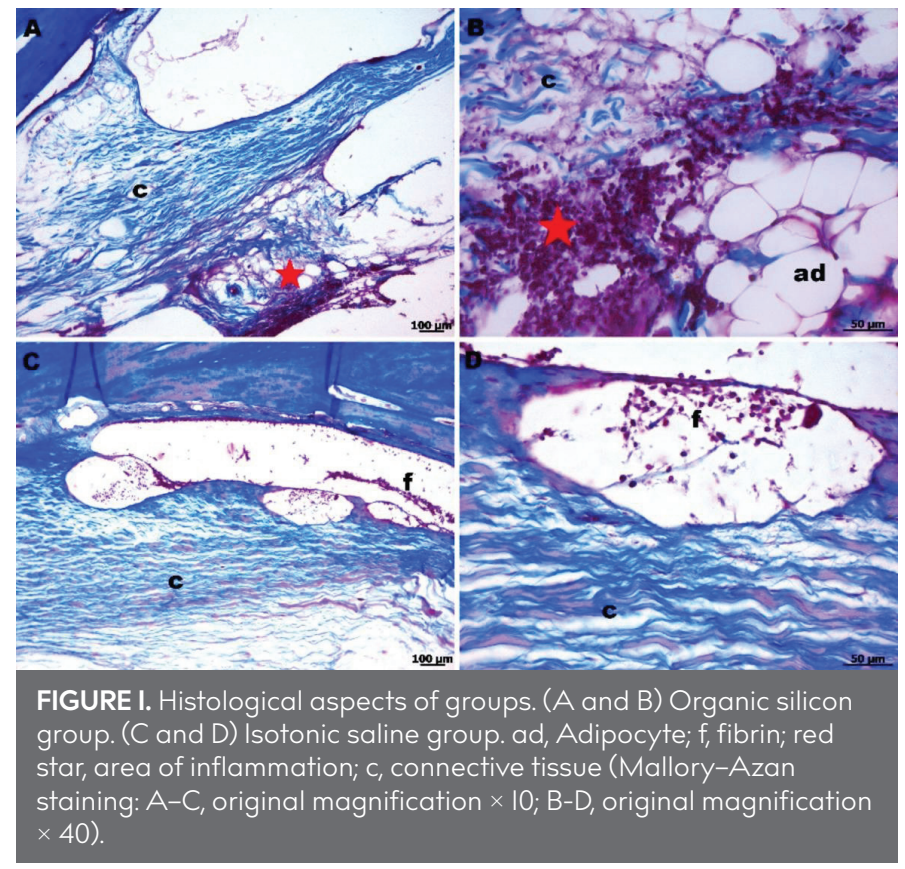

Fibrosis severity was significantly different amongst the study groups ( $p=0.00512$ ). Within the organic silicon group, Grade I fibrotic sites were seen in two TMJs (33.3\%), grade 2 in three TMJs (50\%), and grade 3 in one TMJ (16.7\%). Grade 0 fibrotic areas were observed in all of the joints injected with isotonic saline (Table I).

\section{DISCUSSION}

This study investigated the efficacy of organic silicon prolotherapy for treating TMJ hypermobility. It was hypothesized that organic silicon prolotherapy would produce superior results to the saline control.

TMJ hypermobility can be treated using both surgical and conservative techniques. Considering the neurological complications and difficulties associated with inappropriate applications of surgical techniques (2I), both doctors and patients tend to prefer conservative treatment methods for treating TMJ hypermobility.

Dextrose is commonly used in prolotherapy as it is readily available, inexpensive, and safe to use. There are currently various dextrose concentrations (10\%, 12.5\%, 15\%, 25\%, and 50\%) that are used in the treatment of TMJ hypermobility $(6,12,13,22)$. However, the number of sessions and amounts injected may vary. This may be confusing for clinicians because differing reasons for its application are related to varying concentrations of dextrose but it has shown no superiority to saline as cited by some studies $(18,23)$.

Refai (24) stated that 10\% dextrose prolotherapy was sufficient for significant recovery of symptoms related to TMJ hypermobility. Tomographic views have shown no morphological effect on the bony components of the joint or the condylar position. However, Ungor et al. (I3) mentioned that the maximum mouth opening decreased with 10\% dextrose prolotherapy, but the decrease was not statistically significant.

A 12-week follow-up study by Refai et al. (6) reported that 10\% dextrose can effectively decrease the maximum mouth opening more than in the placebo group. In the study by Kilic et al. (18), $30 \%$ dextrose was not superior to isotonic saline in treating TMJ hypermobility. Both treatments resulted in similarly significant improvements in all visual analog scale measures. However, this study did not find an increase in fibrotic area for TMJs injected with isotonic saline.

Rawand et al. (23) reported that there was no significant difference between different concentrations (10\%,20\%, and 30\%) of dextrose during TMJ prolotherapy. All concentrations were effective in improving clinical symptoms related to TMJ hypermobility. It was specified that 10\% dextrose may be just as adequate in treating TMJ hypermobility as higher concentrations. In one instance, although the patient recovered clinically in the early period following administration of injectable agents, it was observed that the disease recurred in the long term. It is a known fact that examining the histological changes of the agents used produces more objective results than examining the clinical improvements only (25).

Conjoctyl (monomethyl silanetriol salicylate, organic silicon) is an antioxidant used in mesotherapy. Silicon is a component of the structure of elastic connective tissue. It serves as a coenzyme for macromolecular synthesis in the interstitial matrix and increases collagen production $(17,26)$. Since the mechanism of action of the drug and the mechanism of prolotherapy treatment are generally the same, it is thought that conjoctyl may be a possible new alternative to prolotherapy with dextrose. The present study highlights that the number of inflammatory cells and collagen fibers increased in histological images. Furthermore, a clear and significant increase in the fibrotic area was observed. This reflects the accuracy of the hypothesis proposed in the beginning of this study.

In a study by Sangho et al. (27), changes in the collagen structure in rabbits were investigated in the $1^{\text {st }}, 2^{\text {nd }}, 4^{\text {th }}, 8^{\text {th }}$, and $12^{\text {th }}$ weeks after prolotherapy. Changes in the collagen structure were evident in the fourth week following dextrose prolotherapy. A similar 4-week evaluation was performed in the present study. Multiple sessions of dextrose injection were used in the clinical applications of prolotherapy. It was shown that more fibrotic area can be obtained with multiple sessions of organic silicon injections. Furthermore, it can be safely applied to TMJ prolotherapy in a clinical manner because it is already practiced in many areas of medicine such as in dermatology and ophthalmology $(17,28)$.

There were a few limitations present in the study. First, it is not ethical to restrict jaw movements for a long period of time in animal studies. Jaw movement was restricted in the rabbits for one day in this study. Second, the sample size was limited as we were restricted in the number of animals allowed by the ethics committees. 
In conclusion, dextrose is used at different concentrations in prolotherapy. Many studies emphasized the superiority of using dextrose for prolotherapy, and each dose was shown to be successful in treating TMJ hypermobility. However, some other studies reported no difference between using dextrose or saline for prolotherapy. This study suggests that organic silicon may limit hypermobility of the TMJ. Further studies and clinical trials are needed to shed insight on this matter.

Ethics Committee Approval: Ethics committee approval was received for this study from the ethics committee of Gazi University, Ethical Committee for Experimental Research on Animals (G.Ü.ET-I6.004 / 04.02.2016)

Peer-review: Externally peer-reviewed.

Author contributions: Concept - M.E.Y; Design - U.G.; Supervision - M.E.Y; Resource - M.E.Y., U.G.; Materials - M.E.Y., U.G.; Data Collection and/or Processing - M.E.Y., U.G.; Analysis and/or Interpretation - U.G.; Literature Search - M.E.Y; Writing - M.E.Y; Critical Reviews - U.G.

Acknowledgements: The authors would like to thank Prof.Dr. Esra Erdemli and Dr. Derya Özdemir for histological examinations.

Conflict of Interest: Authors have no conflicts of interest to declare.

Financial Disclosure: The authors declared that this study has received no financial support.

\section{REFERENCES}

I. Kummoona R. Surgical reconstruction of the temporomandibular joint for chronic subluxation and dislocation. Int J Oral Maxillofac Surg 2001; 30(4): 344-8. [Crossref]

2. Guven $\mathrm{O}$. Management of chronic recurrent temporomandibular joint dislocations: a retrospective study. J Craniomaxillofac Surg 2009; 37(1):24-9. [Crossref]

3. Sato J, Segami N, Nishimura M, Suzuki T, Kaneyama K, Fujimura K. Clinical evaluation of arthroscopic eminoplasty for habitual dislocation of the temporomandibular joint: comparative study with conventional open eminectomy. Oral Surg Oral Med Oral Pathol Oral Radiol Endod 2003; 95(4): 390-5. [Crossref]

4. Cardoso AB, Vasconcelos BC, Oliveira DM. Comparative study of eminectomy and use of bone miniplate in the articular eminence for the treatment of recurrent temporomandibular joint dislocation. Braz J Otorhinolaryngol 2005; 7I(I):32-7. [Crossref]

5. Akinbami BO. Evaluation of the mechanism and principles of management of temporomandibular joint dislocation. Systematic review of literature and a proposed new classification of temporomandibular joint dislocation. Head Face Med 20II; 7: 10. [Crossref]

6. Refai H, Altahhan O, Elsharkawy R. The efficacy of dextrose prolotherapy for temporomandibular joint hypermobility: a preliminary prospective, randomized, double-blind, placebo-controlled clinical trial. Journal of oral and maxillofacial surgery. J Oral Maxillofac Surg 20Il; 69(12): 2962-70. [Crossref]

7. Miller GA, Murphy EJ. External pterygoid myotomy for recurrent mandibular dislocation. Review of the literature and report of a case. Oral Surg Oral Med Oral Pathol 1976; 42(6): 705-16. [Crossref]

8. Puelacher WC, Waldhart E. Miniplate eminoplasty: a new surgical treatment for TMJ-dislocation. Journal of cranio-maxillo-facial surgery. official publication of the J Craniomaxillofac Surg 1993; 2I(4): 176-8. [Crossref]

9. Guven O. A clinical study on treatment of temporomandibular joint chronic recurrent dislocations by a modified eminoplasty technique. J Craniofac Surg 2008; 19(5): 1275-80. [Crossref]

10. Liddell A, Perez DE. Temporomandibular joint dislocation. Oral Maxillofac Surg Clin North Am 2015; 27(I): 125-36. [Crossref]
II. de Felicio CM, Freitas RL, Bataglion C. The effects of orofacial myofunctional therapy combined with an occlusal splint on signs and symptoms in a man with TMD-hypermobility: case study. Int J Orofacial Myology 2007; 33: 21-9.

12. Hakala RV. Prolotherapy (proliferation therapy) in the treatment of TMD. Cranio 2005; 23(4): 283-8. [Crossref]

13. Ungor C, Atasoy KT, Taskesen F, Cezairli B, Dayisoylu EH, Tosun E, et al. Short-term results of prolotherapy in the management of temporomandibular joint dislocation. The J Craniofac Surg 2013; 24(2): 4II-5. [Crossref]

14. Maynard JA, Pedrini VA, Pedrini-Mille A, Romanus B, Ohlerking F Morphological and biochemical effects of sodium morrhuate on tendons.J Orthop Res 1985; 3(2): 236-48. [Crossref]

15. Klein RG, Eek BC, DeLong WB, Mooney $\vee$. A randomized double-blind trial of dextrose-glycerine-phenol injections for chronic, low back pain. J Spinal Disord Tech 1993; 6(I): 23-33. [Crossref]

16. Reeves KD, Hassanein K. Randomized, prospective, placebo-controlled double-blind study of dextrose prolotherapy for osteoarthritic thumb and finger (DIP, PIP, and trapeziometacarpal) joints: evidence of clinical efficacy. J Altern Complement Med (New York, NY). 2000; 6(4): 31I-20. [Crossref]

17. Kutlubay Z. Evaluation of mesotherapeutic injections of three different combinations of lipolytic agents for body contouring. Journal of cosmetic and laser therapy. J Cosmet Laser Ther 20II; I3(4): 142-53. [Crossref]

18. Comert Kilic S, Gungormus M. Is dextrose prolotherapy superior to placebo for the treatment of temporomandibular joint hypermobility? A randomized clinical trial. Int J Oral Max Surg 2016; 45(7): 813-9. [Crossref]

19. Artuzi FE, Langie R, Abreu MC, Quevedo AS, Corsetti A, Ponzoni $D$, et al. Rabbit model for osteoarthrosis of the temporomandibular joint as a basis for assessment of outcomes after intervention. Brit i Oral Max Surg 2016; 54(5): e33-7. [Crossref]

20. Sairyo K, Biyani A, Goel VK, Leaman DW, Booth R, Jr., Thomas J, et al. Lumbar ligamentum flavum hypertrophy is due to accumulation of inflammation-related scar tissue. Spine 2007; 32(II): E340-7. [Crossref]

21. Guven O. Inappropriate treatments in temporomandibular joint chronic recurrent dislocation: a literature review presenting three particular cases. J Craniofac Surg 2005; 16(3): 449-52. [Crossref]

22. Zhou H, Hu K, Ding Y. Modified dextrose prolotherapy for recurrent temporomandibular joint dislocation. Brit i Oral Max Surg 2014; 52(I): 63-6. [Crossref]

23. Mustafa R, Gungormus M, Mollaoglu N. Evaluation of the Efficacy of Different Concentrations of Dextrose Prolotherapy in Temporomandibular Joint Hypermobility Treatment. J Craniofac Surg 2018; 29(5): e46I-e5. [Crossref]

24. Refai H. Long-term therapeutic effects of dextrose prolotherapy in patients with hypermobility of the temporomandibular joint: a single-arm study with I-4 years' follow up. Brit j Oral Max Surg 2017; 55(5): 465-70. [Crossref]

25. Renapurkar SK, Laskin DM. Injectable Agents Versus Surgery for Recurrent Temporomandibular Joint Dislocation. Oral Maxillofac Surg Clin North Am 2018; 30(3): 343-9. [Crossref]

26. Vedamurthy M. Mesotherapy. Indian J Dermatol Venereol Leprol 2007; 73(I): 60-2. [Crossref]

27. Oh S, Ettema AM, Zhao C, Zobitz ME, Wold LE, An KN, et al. Dextrose-induced subsynovial connective tissue fibrosis in the rabbit carpal tunnel: A potential model to study carpal tunnel syndrome? Hand (New York, NY). 2008; 3(I): 34-40. [Crossref]

28. Chanalet L, Ettaiche M, Baudouin C, Lapalus P. Distribution of salicylate in pigmented rabbit ocular tissues after application of a prodrug, sodium monomethyl trisilanol orthohydroxybenzoate: in vivo and ex vivo studies. Journal of ocular pharmacology and therapeutics : the official J Ocul Pharmacol Ther 1995; II(I): 83-94. [Crossref] 